\title{
Effect of Nutrient Supplementation on Single Cell Protein Production from Watermelon and Pineapple Peels
}

\author{
${ }^{*}$ M. M. Abarshi, ${ }^{1}$ S. B. Mada, ${ }^{1}$ M. I. Amin, ${ }^{1}$ A. Salihu, ${ }^{1}$ A. Garba and ${ }^{1}$ H.A. Mohammad
}

${ }^{1}$ A. Nasidi and $2 D$. A. Maccido

1 Department of Biochemistry, Ahmadu Bello University Zaria, Nigeria

2Department of Microbiology, Ahmadu Bello University Zaria, Nigeria

[ ${ }^{\star}$ Corresponding Author: E-mail: muawiyam@yahoo.co.uk; E: +2348069517779]

\begin{abstract}
The fast growing population of the world has led to an increased demand for protein rich food; this exerts great pressure on food and feed industries to produce sufficient quantities of protein to meet the high nutrient requirements of vulnerable populations (children and women). Single cell protein (SCP) has proven to be a sustainable approach since agricultural residues can be used for the production. In the present study, efforts were made to improve the growth support capacity of watermelon and pineapple fruit peels by submerged fermentation using Saccharomyces cerevisiae. Fruit hydrolysate media supplemented with glucose and nitrogen recorded the highest concentrations of total carbohydrate $(6.6 \mathrm{~g} / \mathrm{L})$ and crude protein $(20 \mathrm{~g} / \mathrm{L})$ on the $16^{\text {th }}$ day of fermentation, as compared to that of the fruit hydrolysate media without supplementation which produced $3.6 \mathrm{~g} / \mathrm{L}$ of total carbohydrate and $5.6 \mathrm{~g} / \mathrm{L}$ of crude protein. Similarly, fruit hydrolysate media supplemented with nitrogen recorded higher content of total carbohydrate $(5.4 \mathrm{~g} / \mathrm{L})$ and crude protein $(20 \mathrm{~g} / \mathrm{L})$; while fruit hydrolysate media supplemented with glucose produced $5.1 \mathrm{~g} / \mathrm{L}$ and $6.0 \mathrm{~g} / \mathrm{L}$ of total carbohydrate and crude protein, respectively. Thus, $S$. cerevisiae produces higher amount of Single Cell Protein by submerged fermentation of pineapple peel hydrolysate $(9.8 \%)$ as compared to watermelon peel hydrolysate $(2.42 \%)$. It was also observed that, the combination of the two fruit peels produces higher SCP than watermelon but lower than pineapple fruit peels. However, supplementation with nutrients (Glucose and Ammonium sulphate) at $2 \%(\mathrm{w} / \mathrm{v})$ greatly increased SCP production in all the fruit combinations. This suggest that microbial growth support capacity of fruit peels can best be improved by addition of nutrient supplements rather than combining different fruit peels. The findings in this study indicated that pineapple peels could serve as a good substrate for SCP production which is strongly influenced by glucose and ammonium sulphate supplementations.
\end{abstract}

Keywords: Yeast, Single Cell Protein, Watermelon, Pineapple, Saccharomyces cerevisiae.

\section{INTRODUCTION}

Proteins are made up of amino acids, which are major components of cells, tissues, and organs. All life forms require proteins for growth and development. Thus, proteins are required in higher quantities than other macromolecules. Inadequate supply of proteins to human body may lead to many deficiency diseases, most of which are alleviated by consumption of protein rich diets (Khan et al., 2010).

Increase in human population was predicted to rise in geometric progression which is in contrast with arithmetic pattern of expected food supply (Olsen et al., 2010). Similarly, the rise in the number of impoverished people necessitates the search for alternative protein sources to address the malnutrition challenges affecting vulnerable populations in developing countries including Nigeria (Ravindra, 2000). Single Cell Protein (SCP) has been used as the alternative and unconventional source for the supply of protein rich food for both animals and humans (Najafpur, 2007). SCPs are dried dead cells of microorganisms (algae, fungi, yeast and bacteria), which are used as flavor enhancer, fat binding agents and a protein rich supplement with the potential to replace conventional sources of protein, such as soymeal or fish meal (Argyro et al., 2006; Jamal et al., 2009; Nasseri et al., 2011). Studies have shown that many agricultural and agroindustrial waste products could be used for the production of SCP. These include orange 
wastes, papaya wastes, onion and sugarcane wastes (Tipparat and Kittikun, 1995), wheat straw (Abou-Hamed, 1993), banana wastes (Saquido et al., 1981; Khan et al., 2011), pineapple (Dhanasekaran et al., 2011), rape straw (Ke et al., 2011) and watermelon (Khan et al., 2011). Some of these wastes though biodegradable, may however cause environmental pollution. Therefore, utilization of these agro-wastes for SCP production help in controlling environmental pollution associated with their disposal.

Non-pathogenic microorganisms recognized as GRAS (generally regarded as safe) can utilize the available nutrients present in agricultural wastes for biomass and cellular growth (Nasseri et al., 2011). Among all the SCP potential strains, Saccharomyces cerevisiae finds global acceptance especially in food and feed formulations (Ravindra, 2000). Processing of pineapple and watermelon generates as high as 30\% wastes (Jamal et al., 2009); these wastes have limited potential as they are often used as animal feed and soil conditioner.

The present study was aimed at evaluating the effect of two supplements (glucose and ammonium sulphate) on $S$. cerevisiae SCP production using watermelon and pineapple wastes as feedstock.

\section{MATERIALS AND METHODS Collection of Fruit Wastes}

Watermelon and pineapple peels were collected immediately after cutting the fruits from Samaru Local Market Zaria. The peels were thoroughly washed under running tap water and then air dried for two days. The partially dried peels were completely dried in an oven (FFD 720, Protech. Ltd, UK) set at $60^{\circ} \mathrm{C}$. The oven dried samples were then ground to powder using an electrical miller (FW 100, Yusung Industrial Ltd, China), and sieved using 2mm mesh sieve (Chaozhou CL, China). Thus the ground samples were packed in transparent polyethene bags and stored at room temperature.

\section{Preparation of Saccharomyces cerevisiae culture}

The S. cerevisiae obtained from Department of Microbiology, Ahmadu Bello University Zaria, was grown on yeast mold agar (3\% yeast extract, 3\% malt extract, $5 \%$ peptone, 10\% glucose and $15 \%$ agar) for 4 days at $28^{\circ} \mathrm{C}$. The inoculum was prepared by washing the growing culture slant three (3) times with $10 \mathrm{ml}$ of sterile distilled water. The mixture was counted using the haemocytometer to obtain the inoculum concentration. McFarland turbidity standard was used to adjust the final microbial concentration to $3 \times 10^{8} \mathrm{cells} / \mathrm{ml}$ (McFarland, 1907).

\section{Preparation of Fruit Hydrolysates}

Watermelon peels, Pineapple peels, and composite (watermelon and pineapple) peels were used as substrate for the SCP production. Procedure described by Mondal et al. (2012) was adopted for the preparation of fruit hydrolysates. The peels $(20 \mathrm{~g})$ were treated with $50 \mathrm{ml}$ of $10 \%(\mathrm{v} / \mathrm{v}) \mathrm{HCl}$ followed by $100 \mathrm{ml}$ of distilled water. The mixture was then incubated in water bath (WB 22, Memmert Ltd, USA) at $100^{\circ} \mathrm{C}$ for one hour. Thereafter, it was allowed to cool and then filtered using Whatman No. 1 filter paper. The filtrate then was diluted with sterile distilled water to a final concentration of $10 \%(\mathrm{v} / \mathrm{v})$.

\section{Fermentation}

The fermentation process was carried out in conical flasks plugged slightly with sterile cotton wool. Four media set up were prepared in 250 $\mathrm{ml}$ conical flask for each of the three fruit hydrolysates. The first medium consists of basal medium composition $(1 \% \quad(\mathrm{w} / \mathrm{v})$ of $\mathrm{KH}_{2} \mathrm{PO}_{4}, 0.5 \%$ (w/v) of $\mathrm{MgSO}_{4} .7 \mathrm{H}_{2} \mathrm{O}, 0.1 \%$ (w/v) $\mathrm{CaCl}_{2}$ and $0.1 \%(\mathrm{w} / \mathrm{v}) \mathrm{NaCl}$ ) and $2 \%(\mathrm{w} / \mathrm{v})$ of $\left(\mathrm{NH}_{4}\right)_{2} \mathrm{SO}_{4}$ that served as a nitrogen source, labelled as nitrogen supplemented media. The second medium was similarly prepared like the first but contained $2 \%(\mathrm{w} / \mathrm{v})$ of glucose which served as carbon source. This was labelled as glucose supplemented media. The third medium labelled as glucose-nitrogen supplemented medium consisted of $2 \%$ (w/v) each of glucose and $\left(\mathrm{NH}_{4}\right)_{2} \mathrm{SO}_{4}$ in addition to the basal media composition. The fourth medium consisted of fruit peel only, labelled as 
fruit waste media. The media were then sterilized using autoclave at $121^{\circ} \mathrm{C}(15 \mathrm{psi})$ for 15 min before fermentation. From the $10 \%$ fruit hydrolysate, $100 \mathrm{ml}$ was measured and transferred into each medium and the $\mathrm{pH}$ was adjusted to 5.5 using $1 \mathrm{M} \mathrm{NaOH}$. Thereafter, $2 \mathrm{ml}$ of the prepared inoculum of $S$. cerevisiae $\left(3 \times 10^{8} \mathrm{CFU} / \mathrm{mL}\right)$ was transferred into each medium followed by incubation at room temperature for a period of 20 days. Each of the set up was prepared in triplicate and the average values were calculated.

\section{Proximate Analysis of the Fruit Peels}

Methods described by AOAC (2006) were used to determine the moisture content, crude protein, crude fat, crude fiber and ash content of the fruit peels.

\section{Chemical Analysis of Biomass production}

After 4 days interval, the total carbohydrate and crude protein of biomass were determined using Anthrone reagent (Hedge and Hofreiter, 1962) and Trichloroacetic acid (TCA) turbidimetric methods (Meulemans, 1960), respectively.

\section{RESULTS AND DISCUSSION \\ Proximate Analysis of Fruit Peels}

The results of the proximate analysis of the watermelon and pineapple fruit peel samples are presented in Table 1 . The crude protein content of watermelon peel was found to be $6.40 \%$; while that of pineapple peel was $3.50 \%$. Similarly, the carbohydrate equivalent to nitrogen free extract content was higher in the watermelon peel (5.53\%) compared to $4.90 \%$ in pineapple peel sample. However, crude fibre was higher in pineapple peel with a value of $9.08 \%$ when compared to values obtained for watermelon peels $(2.42 \%)$. High crude fibre in any sample is desirable as it is known to enhance digestibility (Chibber et al., 1980). Both watermelon and pineapple peel wastes contained varying amounts of fibre as well as total carbohydrate, which on hydrolysis provide carbon source to support microbial growth during fermentation. High moisture content of $80.50 \%$ and $79.92 \%$ were found for watermelon and pineapple peels, respectively. Feed stock moisture content serve as a measure of stability and susceptibility to endogenous and/or exogenous microbial and enzymatic activities (Chakravorty, 2014). The lower the moisture content of any sample the longer is the shelf life. Thus, the two peels used as substrates in this study were found to be suitable for microbial fermentation.

Table 1: Proximate Analysis of Pineapple and Watermelon peels in percentage by weight.

\begin{tabular}{lll}
\hline Parameters & $\begin{array}{l}\text { Watermelon } \\
(\%)\end{array}$ & $\begin{array}{l}\text { Pineapple } \\
(\%)\end{array}$ \\
\hline Moisture & 80.50 & 79.92 \\
Ash & 5.24 & 4.60 \\
Crude fat(lipid) & 6.31 & 7.08 \\
Crude fibre & 2.42 & 9.08 \\
$\begin{array}{l}\text { Crude protein } \\
\text { Nitrogen free }\end{array}$ & 6.40 & 3.50 \\
extract & & \\
(carbohydrate) & 5.53 & 4.90 \\
\hline
\end{tabular}

\section{Chemical Analysis of Biomass \\ Effect of Fruit Peels Combination on Yeast Biomass}

The effect of fruit peels combination (watermelon peels, pineapple peels and watermelon-pineapple composite peels) on biomass of $S$. cerevisiae was investigated. Crude protein and total carbohydrate contents of the biomass produced at every four (4) days interval were measured and the result revealed that the total carbohydrate and crude protein produced was higher in medium consisting of pineapple peels than in the medium containing pineapple and watermelon composite. Fruit waste medium of watermelon peels produced the lowest crude protein and total carbohydrate content (Figures 1-4). This agreed with the findings of Dhanasekaran et al. (2011), which showed that pineapple waste substrate produced highest protein and reducing sugar contents when fermented with two strains of yeasts, Saccharomyces cerevisiae and Candida tropicalis under the same condition.

\section{Effect of Nutrient Supplements on Biomass} Production 
Various components of the media such as inducers, carbon and nitrogen sources and trace elements are required for microbial growth and metabolism. The effects of nitrogen and glucose supplements on yeast growth media for the production of SCP were investigated. The results showed that fruit hydrolysate media supplemented with glucose and nitrogen (Gluc-NSM) recorded the highest concentrations of total carbohydrate $(6.6 \mathrm{~g} / \mathrm{L})$ and crude protein $(20 \mathrm{~g} / \mathrm{L})$ on the $16^{\text {th }}$ day of fermentation, as compared to that of the fruit hydrolysate media (FM) without supplementation which produced $3.6 \mathrm{~g} / \mathrm{L}$ of total carbohydrate and $5.6 \mathrm{~g} / \mathrm{L}$ of crude protein. Similarly, fruit hydrolysate media supplemented with nitrogen recorded higher content of total carbohydrate $(5.4 \mathrm{~g} / \mathrm{L})$ and crude protein $(20$ $\mathrm{g} / \mathrm{L})$ while fruit hydrolysate media supplemented with glucose produced $5.1 \mathrm{~g} / \mathrm{L}$ and $6.0 \mathrm{~g} / \mathrm{L}$ of total carbohydrate and crude protein, respectively. In general, the highest concentration of carbohydrate and protein was observed for the pineapple fruit hydrolysate, followed by watermelon/pineapple composite and the least was recorded for watermelon fruit hydrolysate. The findings in this study showed that glucose had positive influence on SCP production by $S$. cerevisiae. Similar findings of de Azeredo et al. (2007) showed glucose at different concentrations stimulated both growth and hydrolytic enzyme production in Penicillium restrictum using submerged and solid state fermentation and catabolite repression was not observed.

Thus, supplementation with glucose may have a crucial importance in production of SCP by $S$. cerevisiae as shown by the low biomass yield in its absence. Also, low biomass was recorded when nitrogen (Gluc-NSM) source was eliminated; albeit to a lesser extent. This shows the synergistic effect of glucose and ammonium sulphate (as carbon and inorganic nitrogen sources, respectively) on SCP production since their presence greatly influences the growth of $S$. Cerevisiae biomass. Therefore, S. cerevisiae produces higher amount of SCP by submerged fermentation of pineapple peel hydrolysate. This may be attributable to the high fibre content of pineapple peels $(9.8 \%$ compared to $2.42 \%$ of watermelon peels) which yields appreciable amount of carbon upon cellulolytic digestion. It was also observed that, the combination of the two fruit peels produced higher SCP than watermelon but lower than pineapple fruit peels. The observed results were in agreement with the findings of Khan et al. (2011). The addition of nutrient supplements (glucose and ammonium sulphate) on the other hand greatly increased the SCP production of all the fruit combinations; this is similar to the studies reported by Mondal et al. (2012) and Adoki (2008). Glucose supplementation enhanced biomass and thus SCP production as it provides preferentially utilizable source of carbon which is very essential at the initial phase of microbial growth by shortening of the lag phase of growth. The absence of glucose or ammonium sulphate greatly affected the SCP production and this effect became pronounced when ammonium sulphate was excluded. This observation could be due to the low protein content of the fruit peels $(6.40 \%$ and $3.50 \%$ for watermelon and pineapple peels, respectively) than when glucose was excluded. The findings of this study indicated that pineapple peels can serve as a good substrate for SCP production and that the process can be optimized by supplementation with glucose and nitrogen sources. 


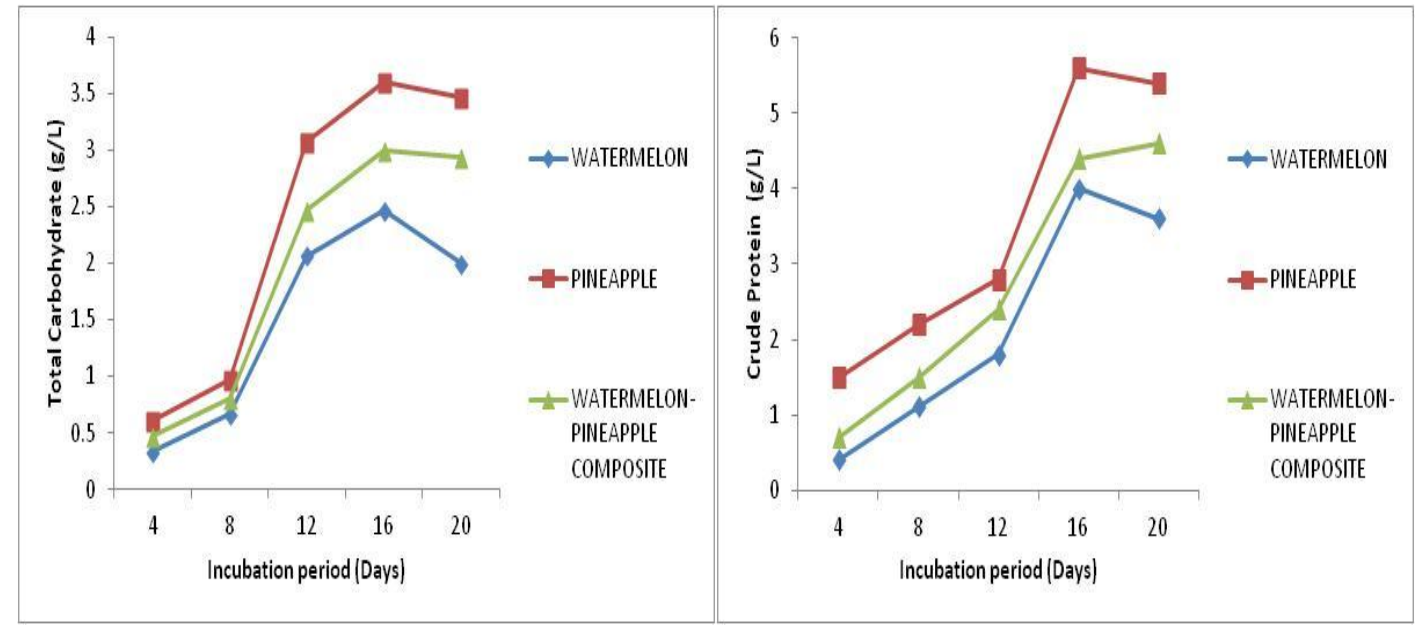

Figure 1: Variation of Total carbohydrate and crude protein contents with incubation time produced by S. cerevisiae in fruit hydrolysate medium with no supplementation

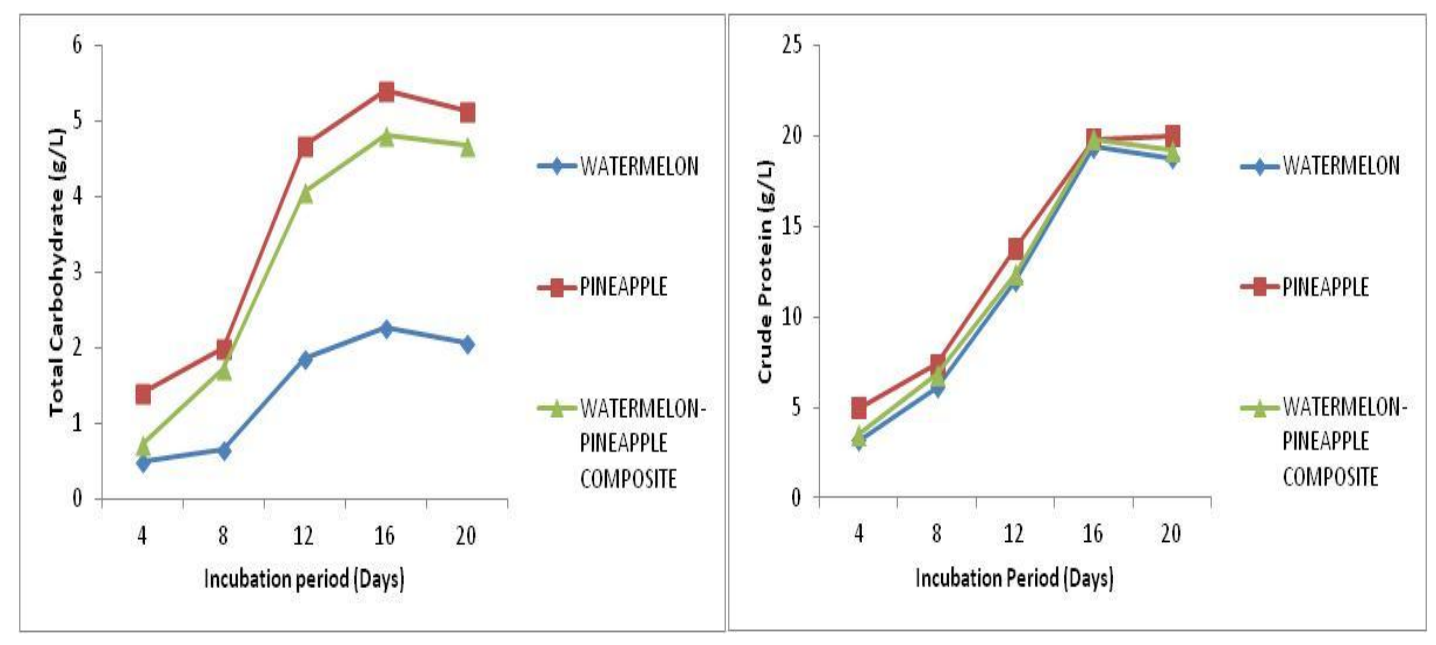

Figure 2: Variation of Total carbohydrate and crude protein contents with incubation time produced by S. cerevisiae in fruit hydrolysate medium supplemented with $2 \%(\mathrm{w} / \mathrm{v})$ ammonium sulphate

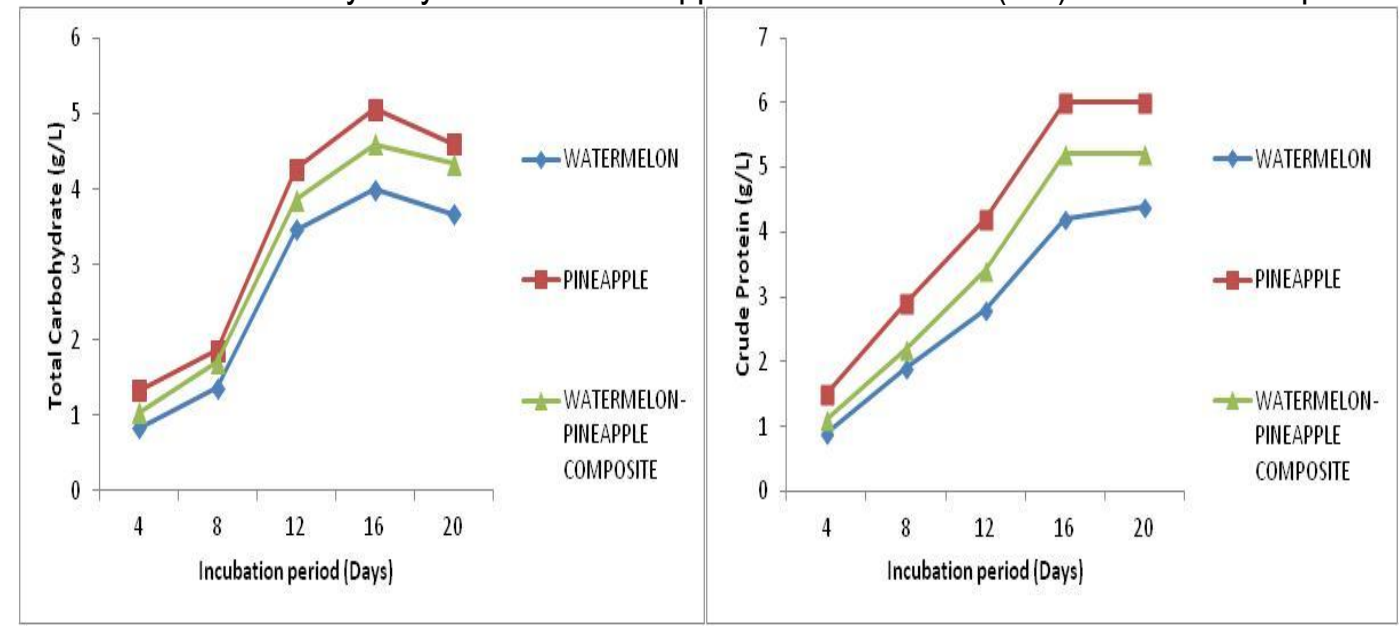

Figure 3: Variation of Total carbohydrate and crude protein contents with incubation time produced by S. cerevisiae in fruit hydrolysate medium supplemented with $2 \%(\mathrm{w} / \mathrm{v})$ glucose 


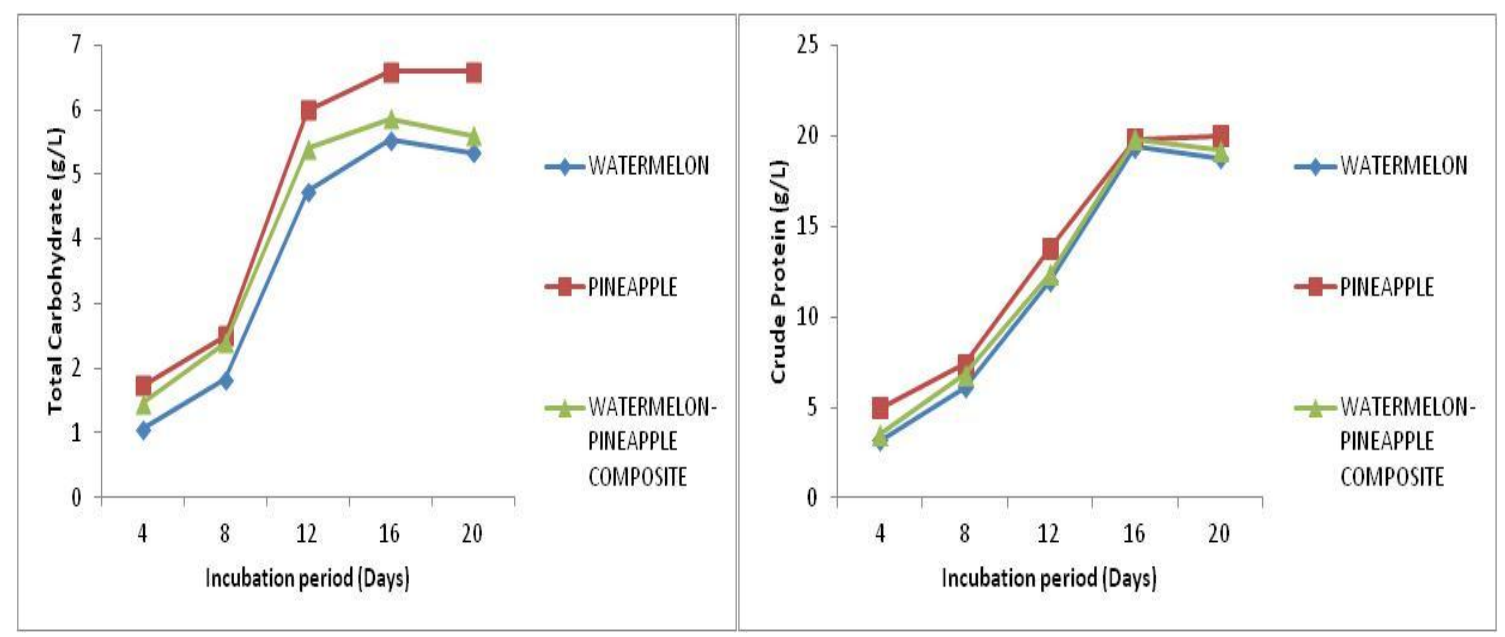

Figure 4: Variation of Total carbohydrate and crude protein contents with incubation time produced by S. cerevisiae in fruit hydrolysate medium supplemented with $2 \%(\mathrm{w} / \mathrm{v})$ each of glucose and ammonium sulphate

\section{CONCLUSION}

In conclusion, our study demonstrated that higher amount of SCP was produced using Saccharomyces cerevisiae by submerged fermentation of pineapple peels than watermelon peels and their composite peels. Also, addition of nutrient supplements such as glucose and ammonium sulphate greatly increased the SCP production. Altogether, the present findings indicated that nutrient supplementations strongly influence SCP production and pineapple peels could be used as potential substrate for SCP production.

\section{REFERENCES}

Abou-Hamed, S. (1993). Bioconversion of wheat straw by yeast into single cell protein. Egyptian Journal Of Microbiology. 28(1): 1-9.

Adoki, A. (2008). Factors affecting yeast growth and protein yield production from orange, plantain and banana wastes processing residues using Candida sp. African Journal of Biotechnology. 7(3): 290-295.

AOAC (2006). The Official Methods of Analysis of AOAC International. 18th Ed. The Association of Official Analytial Chemists, Arlington

Argyro, B., Costas, P. and Athanasios, A. (2006). Production of Food Grade
Yeasts. Food Technology Biotechnology. 44: 409-415.

Chakravorty, J., Ghosh, S., Jung, C. and Meyer-Rochow, V. B. (2004). Nutritional Composition of Chondacris rosea and Brachytrupes orientalis: Two common insects used as food by Tribe of Arunanchal Pradesh India. Journal of Asia-Pacific Entomology, 17: 407415

Chibber, B. A. K., Mertz, E. T., and Axtell, J. D. (1980). In vitro digestibility of hightannin sorghum at different stages of dehulling. Journal of Agricultural and Food Chemistry, 28: 160-161.

de Azeredo, L. A. I., Gomes, P. M., Sant'Anna Jr., G.L., Castilho, L.R. and Freire, D.M.G. (2007). Production and regulation of lipase activity from Penicillium restrictum in submerged and solid-state fermentations. Current Microbiology, 54: 361-365.

Dhanasekaran, D., Lawanya, S., Saha, S., Thajuddin, N., and Panneerselvam, A. (2011). Production of Single Cell Protein from Pineapple wastes using Yeast. Innovative Romanian Food Biotechnology. 8: 6-32.

Hedge, J. and Hofreiter, B. (1962). In: Carbohydrate Chemistry, 17th Ed. 
Whistler R.L. and Be Miller, J.N.(Eds). Academic Press, New York.

Jamal, P., Tompang, M. F. and Alam, M. Z. (2009). Optimization of Media Composition for the Production of Bioprotein from Pineapple skins by Liqiud-state Bioconversion. Journal of Applied Science, 9: 3104-3109.

$\mathrm{Ke}$, L., Wu, Q. and Zhang, D. (2011). Bioconversion of rape straw into a nutritionally enriched substrate by Ganoderma lucidum and yeast. African Journal Biotechnology. 10(29): 56485653.

Khan, M., Khan, S. S., Ahmed, Z. and Siddiqui, S. (2011). Evaluation of Fruit wastes for the production of Single Cell Protein by Saccharomyces cerevisiae. Nanobiotechnica Universal. 2(2): 3338.

Khan, M., Khan, S. S., Ahmed, Z. and Tanveer, A. (2010). Production of Single Cell Protein from Saccharomyces cerevisiae by utilizing Fruit wastes. Nanobiotechnica Universal. 1(2): 127132.

McFarland, J. (1907). Nephelometer: an instrument for media used for estimating the number of bacteria in suspensions used for calculating the opsonic index and for vaccines. Journal of American Medical Association. 14: 1176-8.

Meulemans, O. (1960). Determination of Total protein in spinal fluid with Sulfosalicylic acid and trichloroacetic acid. Clinica Chimica Acta. 5: 757-761.
Mondal, A. K., Sengupta, S., Bhowal, J. and Bhattacharya, D. K. (2012). Utilization of Fruit wastes in production Single Cell Protein. International Journal of Science Environment. 1(5): 430-438.

Najafpur, G. D. (2007). Single Cell Protein: Biotechnology advances. Biochemical Engineering and Biotechnology Advances. 332-341.

Nasseri, A., Rasoul-Amini, S., Morowvat, M. and Ghasemi, Y. (2011). Single Cell Porduction: Porduction and Process. American Journal Of Food Technology. 6: 103-116.

Olsen, D. F., Jorgensen, J. B., Villadsen, J. and Jorgensen, S. B. (2010). Modeling and Simulation of Single Cell Protein Production. $11^{\text {th }}$ International Symposium on Computer Applications in Biotechnology Leuven, Belgium. pp. $502-507$.

Ravindra, A. P. (2000). Value-added food: Single cell protein. Biotechnology Advances, 18: 459-479

Saquido, P. M. A., Cayabyab, V. A. and Vyenco, F.R. (1981). Bioconversion of banana waste into single cell protein. Journal of Applied Microbiology and Biotechnology. 5(3): 321-326.

Tipparat, H. and Kittikun, A. (1995). Optimization of Single Cell Production from Cassava Starch using Schwanniomyces castellii. World Journal of Microbiology and Biotechnology. 11: 607-609. 